\title{
Comparison of minor bleeding complications using dabigatran or enoxaparin after cemented total hip arthroplasty
}

\author{
Csaba Gombár · Gyöngyi Horvath · Hristifor Gálity • \\ Krisztián Sisák · Kálmán Tóth
}

Received: 8 October 2012 / Published online: 2 February 2014

(C) Springer-Verlag Berlin Heidelberg 2014

\begin{abstract}
Background Orally administered chemical thromboprophylactic agents for total hip replacement (THR) have become popular in recent years. Certain clinical trials suggest that the efficacy and the risk of major bleeding after administration of direct thrombin inhibitor dabigatran etexilate are equivalent to the clinical trial comparator, subcutaneous low-molecular-weight heparin enoxaparin. Our aim was to compare and evaluate the incidence of minor haemorrhagic and soft-tissue adverse effects of enoxaparin and dabigatran.

Materials and methods 122 patients who were treated by elective cemented primary THR were enrolled in our quasi-randomised study. Two groups were formed according to which perioperative thromboprophylactic agent was used: 61 patients in enoxaparin group versus 61 patients in dabigatran group. Thigh volume changes, calculated perioperative blood loss, area of haematoma, wound bleeding, duration of wound discharge and intensity of serous wound discharge on postoperative day 3 and day 7 were recorded. Results The duration and intensity of serous wound discharge differed significantly between the two groups. Duration of wound discharge after drain removal was $2.2( \pm 2.7)$ days in the dabigatran group and $1.2( \pm 1.9)$ days in the enoxaparin group $(p<0.05)$. Significant increase in serous discharge was found in the dabigatran group $(p<0.05)$
\end{abstract}

C. Gombár $(\bowtie) \cdot H$. Gálity · K. Sisák · K. Tóth

Department of Orthopaedics, Szent-Györgyi Albert Clinical

Center, University of Szeged, Semmelweis Street 6,

6725 Szeged, Hungary

e-mail: csaba.gombar@yahoo.co.uk

G. Horvath

Department of Physiology, Faculty of Medicine, University

of Szeged, Dóm Square 10, Szeged 6720, Hungary on third and seventh postoperative days compared to the enoxaparin group.

Conclusion Both thromboprophylactic agents were found to have appropriate antithrombotic effects after THR. However, dabigatran was associated with an increased incidence of prolonged serous wound discharge, which might cause longer hospitalization and might instigate the use of prolonged antibiotic prophylaxis.

Keywords Dabigatran · Enoxaparin · Total hip arthroplasty $\cdot$ Thromboprophylaxis $\cdot$ Bleeding complications $\cdot$ Serous wound discharge

\section{Introduction}

Patients undergoing total hip replacement (THR) are at increased risk of venous thromboembolism [15, 26, 30]. Appropriate pharmacologic thromboprophylaxis can significantly reduce the risk of venous thromboembolism (VTE) after THR. Currently recommended pharmacological prophylactic agents for these patients include low-molecularweight heparins (LMWHs), synthetic pentasaccharide, orally administered anti Xa agents, direct thrombin inhibitors, low-dose unfractionated heparin (LDUH), acetylsalicylic acid and adjusted-dose vitamin $\mathrm{K}$ antagonists (VKAs) $[2,21,24]$. Aspirin and VKAs are widely used in North America for THR [21], but are not the favoured therapy for thromboprophylaxis in Europe [2, 35, 42]. LMWHs have been shown to be more effective than unfractionated heparin, aspirin and VKAs across orthopaedic surgical prophylaxis protocols [21, 24, 28, 35]. LMWHs have become the standard of chemical thromboprophylaxis, based on two decades of clinical experience and well-designed studies [42]. 
In Europe, the direct thrombin inhibitor dabigatran etexilate, anti $\mathrm{Xa}$ agents apixaban and rivaroxaban are now approved for hip and knee arthroplasty as options for thromboprophylaxis [3, 4, 42]. The data suggests that the thromboprophylactic efficacies of these new agents are at least equivalent or potentially superior to the clinical trial comparator LMWH, enoxaparin. However, these new agents might be associated with a potentially higher bleeding tendency [10, 12-14, 23, 38, 42]. Recently, several reviews and trials focused on the potentially higher postoperative bleeding and wound infection rate of rivaroxaban and dabigatran [22, 29].

Clinical trials with dabigatran etexilate for THR focused on major and clinically significant bleeding complications, as safety endpoints, with little attention paid to minor bleeding complications, and to surgical outcomes, such as wound healing, drainage, and surgical site infection [12-14].

Our aim was to compare the safety profile of enoxaparin and dabigatran etexilate in the use of primary THR, with particular attention to minor haemorrhagic and soft-tissue adverse effects during the early postoperative period.

\section{Materials and methods}

We prospectively collected and reviewed all patients undergoing primary cemented THR for osteoarthritis or avascular necrosis of the femoral head from February 2011 to March 2012.

These patients were divided into two groups to receive either LMWH enoxaparin (Clexane $^{\circledR}$, Sanofi-Aventis) (Group 1) or the oral direct thrombin inhibitor dabigatran etexilate (Pradaxa ${ }^{\circledR}$, Boehringer Ingelheim International) (Group 2). Patients were enrolled in each group according to our weekly altered medication supply: every odd week enoxaparin and every even week dabigatran was administered. Our study thus can be called a quasi-randomised study.

Non-steroidal anti-inflammatory drugs (NSAIDs) and aspirin were suspended one week prior to surgery. Preoperatively, renal and hepatic function tests, activated partial thromboplastin time (APTT), prothrombin time (PT) and international normalized ratio (INR) were determined. Exclusion criteria included revision surgery, underlying renal and hepatic dysfunction, blood coagulation disorders and anticoagulant intake (acenocoumarol, warfarin, clopidogrel).

Anticoagulants were administered according to orthopaedic guidelines [3, 4, 21, 24]. In Group 1, $40 \mathrm{mg}$ enoxaparin was given subcutaneously $12 \mathrm{~h}$ before operation and at $8 \mathrm{p} . \mathrm{m}$. for the next 28-35 days postoperatively. In Group 2, $220 \mathrm{mg}$ dabigatran etexilate was administered for patients below
75 years of age and $150 \mathrm{mg}$ over 75 years of age. Administration was started $4 \mathrm{~h}$ postoperatively with a half dose (110 or $75 \mathrm{mg}$ ) and then full dose was administered once a day at 8 a.m. for 28-35 days after replacement [3-5, 16].

Surgeries were carried out under general, regional or combined general and regional anaesthesia, depending on what technique was felt most appropriate for the individual patient by the anaesthetic team. All operations were performed by seven consultant orthopaedic surgeons working in a single orthopaedic department, using a direct lateral or Bauer's approach. All patients received a cemented total hip prosthesis. Operations were performed without cell saver or other retransfusion systems. Cefuroxime or clindamycin were used as perioperative antibiotic prophylaxis. Two closed suction drains were used for $24 \mathrm{~h}$ postoperatively. Drainage was collected in scaled bottles. The wound and drain site was covered with Mepore ${ }^{\circledR}$-type bandages after drain removal.

Paracetamol, tramadol and metamizole were administered as pain relief as were required. Physiotherapy started on the first postoperative day, fully weight bearing, with limitation of adduction and external rotation.

Minor bleeding events and major and clinically significant bleedings were recorded according to previous publications and guidelines [1, 12]. Thrombotic events were recorded when clinical signs emerged.

\section{Thrombosis and thromboembolism}

Suspicion of thrombosis was established clinically. If swelling, excessive oedema, discolouration of the limb or a positive Mayer's or Homans' sign were observed, colour duplex sonography of the limb was performed. After 3 months, patients were phoned and asked whether they had been diagnosed or treated with deep vein thrombosis (DVT) or pulmonary embolism (PE) in another hospital. In case of clinical suspicion of pulmonary artery embolism (PAE), a computed tomography of the chest was performed according to our current protocol.

Major and clinically significant bleeding events

Major bleeding was defined as fatal bleeding; overt bleeding associated with $\geq 20 \mathrm{~g} / \mathrm{L}$ fall in haemoglobin; overt bleeding leading to transfusion of $\geq 2$ units packed cells or whole blood; retroperitoneal, intracranial, intraocular or intraspinal bleeding; bleeding warranting treatment cessation or leading to reoperation. Clinically significant bleeding events were defined as spontaneous skin haematoma $\geq 25 \mathrm{~cm}^{2}$, wound haematoma $\geq 100 \mathrm{~cm}^{2}$, spontaneous nose or gingival bleeding $>5 \mathrm{~min}$, spontaneous or intervention-associated macroscopic haematuria lasting $>24 \mathrm{~h}$, and any other bleeding event considered clinically significant [12-14]. 
Table 1 Categories of wound bleeding (postoperative 0-24 h) and serous wound discharge (after drain removal)

\begin{tabular}{ll}
\hline 0 & Clean and dry wound dressing \\
1 & Small spots but not wet through \\
2 & A part of the wound dressing wet through during a day \\
3 & The dressing wet through fully during a day, change and covering gauze were necessary \\
\hline
\end{tabular}

Table 2 Categories of haematoma

\begin{tabular}{ll}
\hline 0 & None $\left(\mathrm{cm}^{2}\right)$ \\
1 & $<100$ \\
2 & $100-200$ \\
3 & $200-300$ \\
4 & $300-400$ \\
5 & $400-500$ \\
6 & $>500$ \\
\hline
\end{tabular}

The calculated perioperative blood loss $(\mathrm{V}, \mathrm{mL})$ was compared between the two groups. For this purpose, the patient's height $(\mathrm{H}, \mathrm{cm})$, weight $(\mathrm{G}, \mathrm{kg})$, preoperative haematocrit $\left(\mathrm{Hct}_{0}\right)$ and haematocrit on the first postoperative day $\left(\mathrm{Hct}_{1}\right)$ were recorded. Patients, who got transfusion in the first $24 \mathrm{~h}$ after the operation, were excluded from this calculation. Nadler's formula was used for calculating the perioperative blood loss [36]:

$\mathrm{V}=\mathrm{EBV} \times \ln \left(\mathrm{Hct}_{0} / \mathrm{Hct}_{1}\right)$

Estimated blood volumes (EBV) were calculated with the following formula:

$\mathrm{EBV}=\mathrm{A} \times \mathrm{H}^{0,725} \times \mathrm{G}^{0,425}-\mathrm{B}$

where $A=0.0236$ for men; $A=0.0248$ for women; $B=1.229$ for men; $B=1.954$ for women.

\section{Minor bleeding events}

Minor bleeding was defined as wound bleeding, serous wound discharge classified in four categories and wound haematoma smaller than $100 \mathrm{~cm}^{2}$ (Tables 1,2).

\section{Wound bleeding and serous wound discharge}

Wound bleeding was defined as bleeding of the surgical wound into the dressing in the first postoperative $24 \mathrm{~h}$, until drain removal. Its intensity was categorized according to Table 1 . Serous wound discharge was defined as the oozing of the surgical wound and drain site after drain removal. Discharge was examined every day. The duration in days and intensity of serous wound discharge were observed and recorded. The exact amount was documented on the third and seventh postoperative days, when wound dressings were followed up above the surgical and drain site, and examined and documented according to the established categories (Table 1). The cessation of the serous ooze was precisely documented after the surgical intervention. Subgroup analysis was performed regarding the last patient on each particular list, to assess whether the shorter period between the completion of surgery and the next dose of anticoagulant would influence wound discharge/drainage.

\section{Haematoma}

The area of haematoma (blood suffusion) on the skin surface was measured and patients were referred according to our established categories (Table 2).

\section{Change in thigh volume}

Excessive oozing may not only present with discharge but also with increased thigh volume after THR [19]. Jones and Pearson developed an anthropometric method for correct estimation of leg volume by partitioning the volume of the leg into six segments which are similar to truncated cones [31]. Three segments' data were sufficient to measure for calculating the thigh volume. Briefly, with the patient standing erect and the feet slightly apart, four circumferences were taken with a metric tape at predetermined sites: the gluteal furrow, one-third of the subischial height up from the tibial-femoral joint space, the minimum circumference above the knee, the maximum circumference around the knee. The heights above the floor level for each circumference were measured by stadiometer [40]. Thigh volume $(\mathrm{ml})$ was then calculated by summing up the volumes of three truncated cones. All equations were previously entered into the Microsoft Excel software for faster results (Microsoft ${ }^{\mathrm{TM}}, 2007$ ).

\section{Statistics}

Data are shown as mean \pm standard deviation (SD). Statistical analysis was done using $t$ test, Chi-square test and ANOVA using StatSoft ${ }^{\circledR}$ Statistica v.9 statistical software. A $p$ value of $<0.05$ was considered significant.

\section{Results}

122 patients were enrolled, 61 into each group. The number and descriptive data of the patients are presented in Table 3 . 
Table 3 Patient

characteristics $\pm \mathrm{SD}(\min -\max )$

\begin{tabular}{|c|c|c|}
\hline & Enoxaparin & Dabigatran \\
\hline Number of patients & 61 & 61 \\
\hline Gender & $16 \delta^{2} / 45$ 우 & $17 \delta^{*} / 449$ \\
\hline Average age & $69 \pm 9.7(47-85)$ & $69 \pm 7.6(52-86)$ \\
\hline Height (cm) & $164 \pm 8.9(150-189)$ & $164 \pm 8.0(148-186)$ \\
\hline Weight $(\mathrm{kg})$ & $77 \pm 14.1(45-100)$ & $76 \pm 11.6(48-99)$ \\
\hline $\operatorname{BMI}\left(\mathrm{kg} / \mathrm{m}^{2}\right)$ & $28.5 \pm 4.8(19.1-37.7)$ & $28.3 \pm 4.3(17.9-40.9)$ \\
\hline Estimated blood volume (mL) & $4,464 \pm 743.8(2,775-6,241)$ & $4,458 \pm 637.9(2,859-5,893)$ \\
\hline Haematocrit before surgery & $0.40 \pm 0.038(0.30-0.50)$ & $0.40 \pm 0.038(0.31-0.50)$ \\
\hline Haemoglobin before surgery $(\mathrm{g} / \mathrm{L})$ & $134.7 \pm 15.7(94-176)$ & $135.9 \pm 13.5(101-172)$ \\
\hline Duration of surgery (min) & $77 \pm 18.8(50-140)$ & $74 \pm 15.8(50-120)$ \\
\hline Anaesthesia general/regional/combination & $16 / 38 / 7$ & $16 / 37 / 8$ \\
\hline
\end{tabular}

Table 4 Significant bleeding complication in our study according to guidelines of previous publications

\begin{tabular}{lcc}
\hline & Enoxaparin $(n=61)$ & Dabigatran $(n=61)$ \\
\hline Clinically overt bleeding leading to transfusion of $\geq 2$ units packed cells & $4(6.6)$ & $5(8.2)$ \\
Wound haematoma $\geq 100 \mathrm{~cm}^{2}$ & $29(47.5)$ & $33(54.1)$ \\
Intervention-associated macroscopic haematuria lasting $>24 \mathrm{~h}$ & $0(0.0)$ & $1(1.6)$ \\
\hline
\end{tabular}

Data are shown as number of events, percentage in brackets $(\%)$

Characteristics of patients were similar, without any significant differences.

No patients developed clinical features of DVT during the treatment and follow-up period, therefore duplex sonography was not performed. No PAE events or deaths occurred during the hospitalization and 3 months after the operation.

There were no significant differences between the two groups in major bleeding events (Table 4). 22 patients in the dabigatran group and 21 patients in the enoxaparin group needed transfusion in the postoperative period.

No significant differences were found between the two groups in volume of blood loss during surgery: $300 \mathrm{ml}$ $( \pm 137.23)$ in dabigatran group and $314 \mathrm{ml}( \pm 197.32)$ in the enoxaparin group was measured. Volume of the postoperative drainage also did not differ significantly: $470.82 \mathrm{ml}$ $( \pm 276.85)$ in dabigatran group and $471.64 \mathrm{ml}( \pm 253.3)$ in enoxaparin group was found. There were no significant differences in perioperative calculated blood loss, which were $1,072.4 \mathrm{ml}( \pm 586.6)$ in the dabigatran group and $1,152.3 \mathrm{ml}( \pm 486)$ in the enoxaparin group. Subgroup analysis did not show any significant differences in wound bleeding/discharging and drainage volume regarding to patient's position on the operation schedule (first or last on the list). No significant differences were found in the total blood loss as calculated by a total drop in preoperative and postoperative first day haemoglobin level: $30.7 \mathrm{~g} / \mathrm{L}( \pm 13.5)$ using dabigatran and $28.3 \mathrm{~g} / \mathrm{L}( \pm 12.7)$ using enoxaparin. Eight patients from the enoxaparin group and three patients
Table 5 Wound bleeding incidences in the two groups

\begin{tabular}{lllll}
\hline Category & 0 & 1 & 2 & 3 \\
\hline Enoxaparin $(n=61)$ & $2(3.3)$ & $24(39.3)$ & $16(26.2)$ & $19(31.2)$ \\
Dabigatran $(n=61)$ & $1(1.6)$ & $23(37.7)$ & $18(29.5)$ & $19(31.2)$ \\
\hline
\end{tabular}

Data are shown as number of events, percentage in brackets (\%). Definitions of categories are found in Table 1

from the dabigatran group received transfusion in the first $24 \mathrm{~h}$ after their operations, therefore they were excluded from this calculation and comparison of postoperative haemoglobin drops.

Wound bleeding also did not show significant differences between the two groups (Table 5).

Data on haematoma frequency are presented in Table 6. There was no statistical significance between groups.

Significant increases of thigh volumes were observed in both groups on the seventh postoperative day compared to preoperative volumes, however, no significant difference was found between the two groups (Fig. 1).

In contrast to these, the main differences between the two groups are in the duration and intensity of serous wound discharge. Duration of wound discharge was 2.2 $( \pm 2.7)$ days in the dabigatran group and $1.2( \pm 1.9)$ days in the enoxaparin group after drain removal $(p<0.05)$ (Fig. 2). Significantly, higher intensity of wound draining was found in the dabigatran group $(p<0.05)$ (Table 7 ; Fig. 3). 
Table 6 Haematoma frequency

\begin{tabular}{llllllll}
\hline Category & 0 & 1 & 2 & 3 & 4 & 5 & 6 \\
\hline Enoxaparin $(n=61)$ & $23(37.7)$ & $9(14.8)$ & $6(9.8)$ & $10(16.4)$ & $4(6.6)$ & $2(3.3)$ & $7(11.4)$ \\
Dabigatran $(n=61)$ & $22(36.1)$ & $6(9.8)$ & $15(24.6)$ & $6(9.8)$ & $5(8.2)$ & $5(8.2)$ & $2(3.3)$ \\
\hline
\end{tabular}

Data are shown as number of events, percentage in brackets (\%). Definitions of categories are found in Table 2

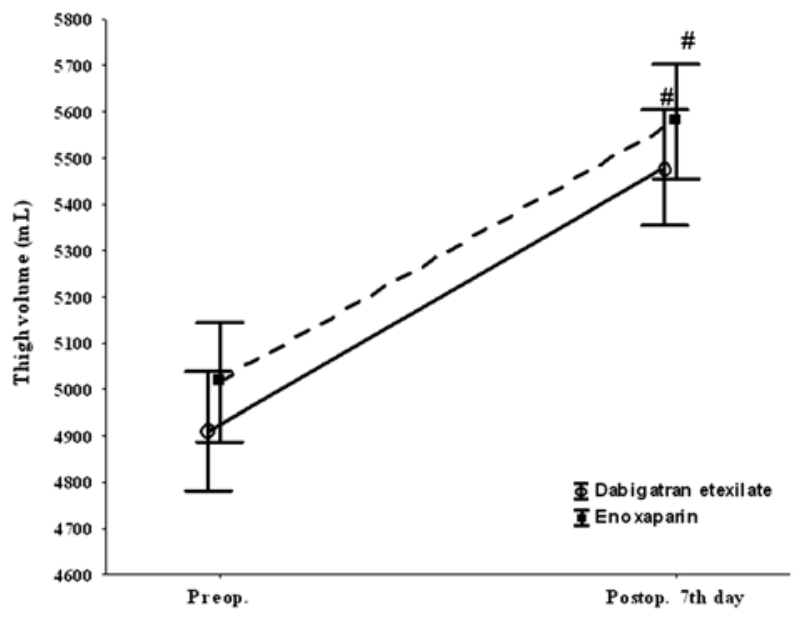

Fig. 1 Postoperative thigh volume increase. Significant increases (hash) of thigh volumes on the seventh postoperative day were found in both groups compared to preoperative volumes, however, no significant difference was found between the two groups $(p<0.05)$

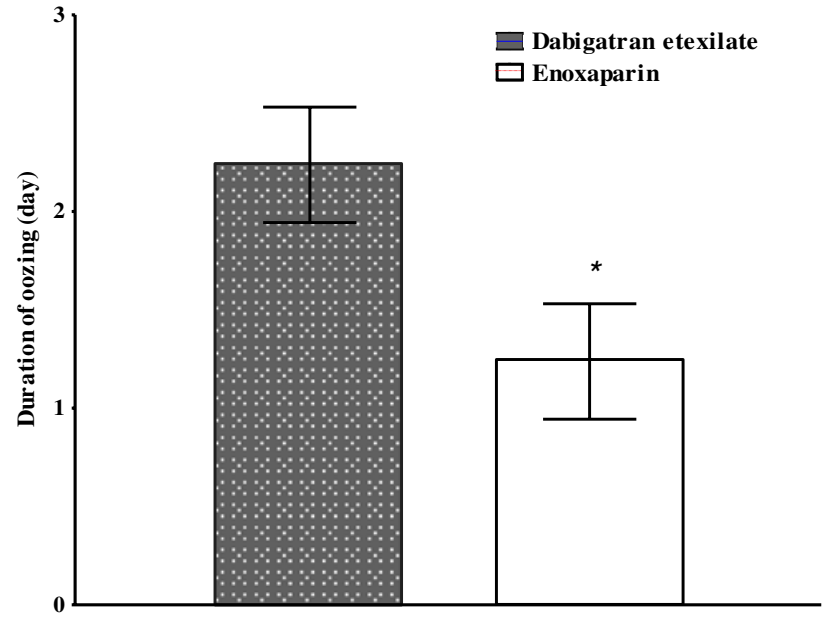

Fig. 2 Duration of drain wound oozing. Duration of drain wound oozing in days. Asterisk means significant difference between the two groups $(p<0.05)$. Duration of serous wound discharge was $2.2( \pm 2.7)$ days in the dabigatran group and $1.2( \pm 1.9)$ days in the enoxaparin group

\section{Discussion}

Patients undergoing THR are under increased risk for postoperative DVT and VTE events $[15,26,30]$, with up to
42-60 \% having an asymptomatic venographically proven DVT and 16-32\% having a PE in the absence of any thromboprophylactic measures [7].

Despite decades of clinical experience and a plethora of studies, the ideal method of VTE prophylaxis remains controversial. Chemical thromboprophylaxis mainly reduces risk of asymptomatic DVT and only marginally PE, but does not reduce fatal VTE and death rate [44].

In 2012 [24], the American College of Chest Physicians (ACCP) and the American Academy of Orthopaedic Surgeons (AAOS) suggested using either LMWH, fondaparinux, apixaban, dabigatran, rivaroxaban, LDUH, acetylsalicylic acid, adjusted-dose VKA (all Grade 1B) or an intermittent pneumatic device (Grade 1C) after THR. Even prior to this, LMWHs have become standard thromboprophylactic drugs [42]. Enoxaparin, is one of the most favoured subcutaneously administered antithrombotic agent in Europe, was used as comparator during clinical trials with dabigatran etexilate. Trials with the new direct thrombin inhibitor investigated the major and clinically significant bleedings as safety endpoints, however, minor bleeding events were mostly ignored and their exact details were unknown [11-14]. Table 8 shows collected bleeding complications of the relevant doses in the studies with dabigatran etexilate.

The BISTRO I determined the safe therapeutic range of dabigatran etexilate following THR [11]. At the end of this study, the lack of any major bleeding episodes and potentially higher number of minor bleeding events were explained by inaccurately defined bleeding complication criteria.

Different doses of dabigatran were compared during BISTRO II study [12]. The higher doses of dabigatran were significantly more effective than enoxaparin, although also resulted in increased bleeding events.

RE-NOVATE study declared that the 150 or $220 \mathrm{mg}$ doses of dabigatran etexilate are as effective as $40 \mathrm{mg}$ enoxaparin for the prevention of venous thromboembolism, with similar safety profile [14].

RE-NOVATE II study found similar risk of bleeding and safety profiles in $220 \mathrm{mg}$ dabigatran etexilate and $40 \mathrm{mg}$ enoxaparin groups after THR [13]. Minor and clinically relevant non-major bleeding was firstly mentioned, as summarized results, which showed raised incidence of minor wound complications using dabigatran etexilate. 
Table 7 Number of patients with different categories of serous wound discharge

\begin{tabular}{|c|c|c|c|c|c|c|c|c|}
\hline \multirow[b]{2}{*}{ Category } & \multicolumn{4}{|l|}{ Day 3} & \multicolumn{4}{|l|}{ Day 7} \\
\hline & All & 1 & 2 & 3 & All & 1 & 2 & 3 \\
\hline Enoxaparin $(n=61)$ & $13(21.3)$ & $5(8.2)$ & $2(3.3)$ & $6(9.8)$ & $3(4.9)$ & $2(3.3)$ & $0(0)$ & $1(1.6)$ \\
\hline Dabigatran $(n=61)$ & $23(37.7)$ & 7 (11.4) & $2(3.3)$ & $14(23.0)$ & $10(16.4)$ & $3(4.9)$ & $3(4.9)$ & $4(6.6)$ \\
\hline
\end{tabular}

Data are shown as number of events, percentage in brackets (\%). Definitions of categories are found in Table 1

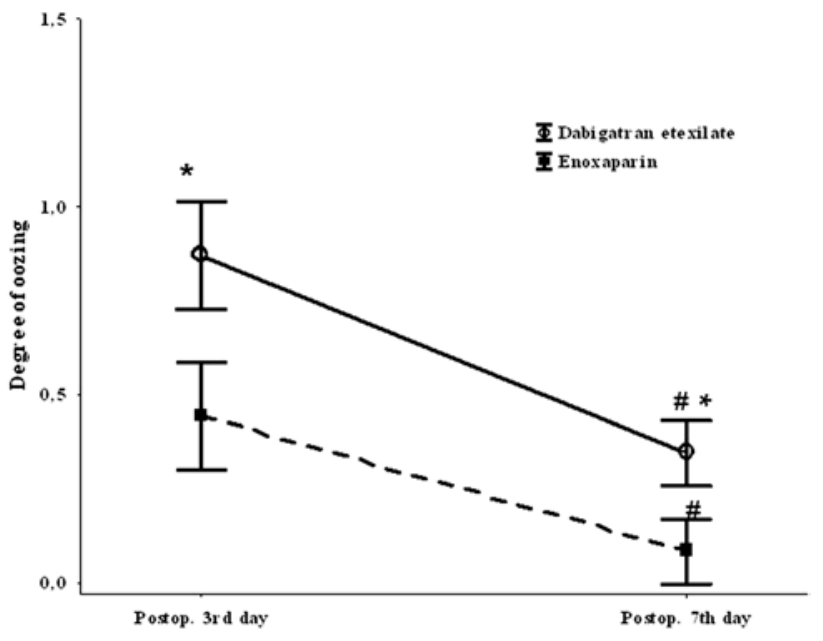

Fig. 3 Intensity of serous wound discharge. (Asterisk) significantly higher serous wound discharge was found in the dabigatran group on the third and seventh postoperative days. Hash means significant decrease in serous wound discharge was measured in both groups between third and seventh postoperative days

According to current guidelines, the recommended VTE prophylaxis duration is 28-35 days after THR [3, 4, 16, 24].

Enoxaparin exhibits predictable anticoagulation and can be given at fixed doses, but subcutaneous administration limits its use in the outpatient setting. Disadvantages include an indirect method of action, risk of heparininduced thrombocytopenia (HIT), allergic reactions due to its animal origin and short elimination half-life [27]. In case of need, there is ability to monitor the thrombocyte count, the efficacy (APTT) and administer protamine sulphate as antidote [16, 25].

Dabigatran etexilate is just as effective and safe as LMWHs, furthermore, it does not have the above-mentioned disadvantages. However, it lacks the option to be monitored or reversed. [16, 25].

Our clinical experiences with elevated serous wound discharge prodded us to explore the background of development of dabigatran focusing on minor bleeding events and design a study to prove our observations. No previous similar detailed reports are available with dabigatran on the minor, but clinically important, side-effects of haematoma around operated area, oozing from the wound and prolonged discharge from the drain site. A previous study in the United Kingdom found significantly more delayed wound discharges after taking dabigatran postoperatively. Based on their study, they no longer prescribe dabigatran from the day of surgery but prefer to prescribe dalteparin until the wound is dry postoperatively and then discharge the patient home on oral dabigatran [22].

In our study, the incidence of major and clinically significant bleeding events was higher in both groups compared to dabigatran development trials [11-14], although the same previous guidelines were considered. Patients were equally divided and operated by seven experienced orthopaedic surgeons using the same surgical technique. No significant differences were seen in terms of individual complication rates of surgeons.

Although our study involved a relatively small number of patients, we have managed to find significant differences in serous wound discharge. However, no such differences were found in terms of skin haematoma formation. There is currently no study that examined the long-term wound complication rate using dabigatran, however, there are publications which found elevated incidence of bleeding complications and wound infection taking rivaroxaban [29]. Our aim was not to establish the pharmacological explanation of minor bleeding complications. We can hypothetise that the earlier postoperative administration of these new oral anticoagulants might be responsible for the increased incidence of postoperative wound ooze.

A significant increase in thigh volume was found in our study in both groups between the initial and postoperative seventh day data, however, no significant differences were found between the two groups. Although our study involved a relatively small number of patients, we still found significant differences in serous wound discharge rates. There are currently no studies on increased infection rates with dabigatran etexilate, but a higher incidence of bleeding complications and importantly also wound infection was reported for rivaroxaban [29]. We can only hypothesise that the (too) early postoperative administration of these new oral anticoagulants might be responsible for the increased incidence of postoperative wound ooze. The current ACCP guidelines recommend to start LMWH as thromboprophylaxis after $12 \mathrm{~h}$ or even later postoperatively rather than within $4 \mathrm{~h}$ or 
Table 8 Comparable bleeding events during the treatment periods of each study

\begin{tabular}{|c|c|c|c|c|}
\hline Studies & Total population & Major bleeding events (\%) & $\begin{array}{l}\text { Clinically significant bleeding } \\
\text { events }(\%)\end{array}$ & $\begin{array}{l}\text { Minor bleeding } \\
\text { events }(\%)\end{array}$ \\
\hline \multicolumn{5}{|l|}{ BISTRO I } \\
\hline Dabigatran $50 \mathrm{mg}$ bid & 30 & 0 & n.a. & $2(7.4)$ \\
\hline Dabigatran $150 \mathrm{mg}$ bid & 29 & 0 & n.a. & $26(89.7)$ \\
\hline Dabigatran $300 \mathrm{mg}$ qd & 46 & 0 & n.a. & $41(89.1)$ \\
\hline \multicolumn{5}{|l|}{ BISTRO II } \\
\hline Dabigatran $50 \mathrm{mg}$ bid & 265 & 0 & $5(1.9)$ & $11(4.2)$ \\
\hline Dabigatran $150 \mathrm{mg}$ bid & 266 & $10(3.8)$ & $11(4.1)$ & $23(8.6)$ \\
\hline Dabigatran $300 \mathrm{mg}$ bid & 258 & $12(4.7)$ & $12(4.7)$ & $22(8.5)$ \\
\hline Enoxaparin $40 \mathrm{mg} \mathrm{qd}^{\mathrm{c}}$ & 270 & $6(2.2)$ & $7(2.6)$ & $14(5.2)$ \\
\hline \multicolumn{5}{|l|}{ RE-NOVATE } \\
\hline Dabigatran $220 \mathrm{mg} \mathrm{qd}^{\mathrm{a}, \mathrm{b}}$ & 1,146 & $23(2.0)$ & $48(4.2)$ & $70(6.1)$ \\
\hline Dabigatran $150 \mathrm{mg} \mathrm{qd}^{\mathrm{a}, \mathrm{b}}$ & 1,163 & $15(1.3)$ & $55(4.7)$ & $72(6.2)$ \\
\hline Enoxaparin $40 \mathrm{mg} \mathrm{qd}^{\mathrm{c}}$ & 1,154 & $18(1.6)$ & $40(3.5)$ & $74(6.4)$ \\
\hline \multicolumn{5}{|l|}{ RE-NOVATE II } \\
\hline Dabigatran $220 \mathrm{mg} \mathrm{qd}^{\mathrm{ab}}$ & 1,010 & $14(1.4)$ & $23(2.3)$ & $61(6.0)$ \\
\hline Enoxaparin $40 \mathrm{mg} \mathrm{qd}^{\mathrm{c}}$ & 1,003 & $9(0.9)$ & $20(2.0)$ & $54(5.4)$ \\
\hline
\end{tabular}

Data are $n(\%)$

Bid, twice daily; $q d$, once daily; n.a., means not applicable

${ }^{a}$ For all bleeding outcomes, none of the differences between each dabigatran etexilate dose and enoxaparin were significant

b Starting with a half dose 1-4 h postoperatively

c Starting the evening before surgery

less preoperatively or $4 \mathrm{~h}$ or less postoperatively as recommended by the manufacturer [16, 24].

An early study in 1981 mentioned anticoagulant therapy causing wound haematoma and wound draining as risk factor of deep infection after THR [6]. It is controversial whether a discharging wound can be an important source of late periprosthetic infection [6, 17], however, some authors observed positive correlation between discharge from the wound and late deep infection [18, 45]. The first report on minor, but clinically important sideeffects found an increased incidence of bruising and prolonged discharge from drain site after enoxaparin compared to control group without thromboprophylaxis [43]. The "clexane-knee" entity was well known over the early introduction period of enoxaparin. Minor bleeding complications caused reluctance in the use of LMWHs at that time [20]. A questionnaire study of hip and knee surgeons found in 1997 that $48 \%$ of surgeons had stopped using LMWHs because of bruising, ooze, bleeding problems and formation of haematoma [33]. Over the last two decades, we have come to accept the minor side-effects of enoxaparin. The new dabigatran etexilate can potentially cause more prolonged oozing from the drain site and an increased incidence of serous wound discharge, which might prevent this agent from being widely used in orthopaedic surgery.
It is potentially unsafe to discharge a patient with an oozing wound or drain site, even when his/her postoperative state would otherwise allow this, which might lead to longer hospitalization and prolonged antibiotic prophylaxis. This could potentially lead to increased costs $[8,9]$.

Our study has several strengths and weaknesses. It was performed in single large volume tertiary referral university department, using consecutive patients, and a standardized surgical technique. The two compared groups were found to be demographically identical. Perioperative blood loss was monitored comprehensively (theatre, drain, haemoglobin concentration, wound haematoma, drainage, serous discharge). Arguably, our patient population is still relatively small, as establishing differences in reoperation or infection rate requires large multi-centre studies. We did use drains in primary THR patients, which is although not an unheard technique, but relatively less common today [32, 39]. We felt that this was not relevant regarding the aim of our study, as drain usage was universal, affecting both groups equally. The use of suction drains remains controversial after joint arthroplasty. There is increasing evidence suggesting that drains are not routinely required as they do not have any positive effect $[34,37,41]$.

Increased incidence of prolonged discharge from the drain site and the increased incidence of elevated serous wound discharge were found using dabigatran etexilate. 
Further, large-scale multi-center studies could help establish the clinical relevance and effect on outcome of bleeding complications and more importantly potentially increased rates of infection associated with dabigatran use.

Acknowledgements: This study complies with the current laws of Hungary. The ethics committee of Clinical Research Coordination Center of Szent-Györgyi Albert Clinical Center, University of Szeged approved the study.

Conflict of interest: K. Tóth was investigator during the BISTRO II, RE-NOVATE and RE-NOVATE II, and received grants for enrolling patients.

\section{References}

1. The European Agency for the Evaluation of Medicinal Products, Committee for Medicinal Products for Human Use (CHMP), Guideline on clinical investigation of medicinal products for prophylaxis of high intra- and post-operative venous thromboembolic risk. http://www.ema.europa.eu/docs/en_GB/document_library/ Scientific_guideline/2009/09/WC500003301.pdf

2. International Consensus Statement (guidelines according to scientific evidence) (2006) Prevention and treatment of venous thromboembolism. Int Angiol 25(2):101-161

3. National Institute for Health and Clinical Excellence (NICE) (2010) Venous thromboembolism—reducing the risk: NICE guideline. http://guidance.nice.org.uk/CG92/NICEGuidance/pdf/ English

4. Scottish Intercollegiate Guidelines Network (SIGN) (2010) Prevention and management of venous thromboembolism. http://www.sign.ac.uk/guidelines/fulltext/122/index.html

5. European Medicines Agency (2011) Pradaxa. Summary of product characteristics. http://www.emea.europa.eu/docs/en_GB/document_library/EPAR_-_Summary_for_the_public/human/00082 9/WC500041060.pdf

6. Andrews HJ, Arden GP, Hart GM, Owen JW (1981) Deep infection after total hip replacement. J Bone Joint Surg $\mathrm{Br}$ 63-B(1):53-57

7. Arcelus JI, Kudrna JC, Caprini JA (2006) Venous thromboembolism following major orthopedic surgery: what is the risk after discharge? Orthopedics 29(6):506-516

8. Bonnevialle P, Bonnomet F, Philippe R, Loubignac F, RubensDuval B, Talbi A et al (2012) Early surgical site infection in adult appendicular skeleton trauma surgery: a multicenter prospective series. Orthop Traumatol Surg Res 98(6):684-689

9. Dolinger O, Souza GM, Melo GB, Filho PPG (2010) Surgical site infections in primary total hip and knee replacement surgeries, hemiarthroplasties, and osteosyntheses at a Brazilian university hospital. Am J Infect Control 38(3):246-248

10. Eriksson BI, Borris LC, Friedman RJ, Haas S, Huisman MV, Kakkar AK et al (2008) Rivaroxaban versus enoxaparin for thromboprophylaxis after hip arthroplasty. N Engl J Med 358(26):2765-2775

11. Eriksson BI, Dahl OE, Ahnfelt L, Kalebo P, Stangier J, Nehmiz G et al (2004) Dose escalating safety study of a new oral direct thrombin inhibitor, dabigatran etexilate, in patients undergoing total hip replacement: BISTRO I. J Thromb Haemost 2(9): 1573-1580

12. Eriksson BI, Dahl OE, Buller HR, Hettiarachchi R, Rosencher N, Bravo ML et al (2005) A new oral direct thrombin inhibitor, dabigatran etexilate, compared with enoxaparin for prevention of thromboembolic events following total hip or knee replacement: the BISTRO II randomized trial. J Thromb Haemost 3(1):103-111

13. Eriksson BI, Dahl OE, Huo MH, Kurth AA, Hantel S, Hermansson K et al (2011) Oral dabigatran versus enoxaparin for thromboprophylaxis after primary total hip arthroplasty (RE-NOVATE II*). A randomised, double-blind, non-inferiority trial. Thromb Haemost 105(4):721-729

14. Eriksson BI, Dahl OE, Rosencher N, Kurth AA, van Dijk CN, Frostick SP et al (2007) Dabigatran etexilate versus enoxaparin for prevention of venous thromboembolism after total hip replacement: a randomised, double-blind, non-inferiority trial. Lancet 370(9591):949-956

15. Evarts CM, Feil EJ (1971) Prevention of thromboembolic disease after elective surgery of the hip. J Bone Joint Surg Am 53(7):1271-1280

16. Falck-Ytter Y, Francis CW, Johanson NA, Curley C, Dahl OE, Schulman S et al (2012) Prevention of VTE in orthopedic surgery patients: antithrombotic Therapy and Prevention of Thrombosis, 9th ed: American College of Chest Physicians Evidence-Based Clinical Practice Guidelines. Chest 141(2 Suppl):e278S-e325S

17. Franco JA, Baer H, Enneking WF (1977) Airborne contamination in orthopedic surgery. Evaluation of laminar air flow system and aspiration suit. Clin Orthop Relat Res 122:231-243

18. Freeman MA, Challis JH, Zelezonski J, Jarvis ID (1977) Sepsis rates in hip replacement surgery with special reference to the use of ultra clean air. Arch Orthop Unfallchir 90(1):1-14

19. Fujisawa M, Naito M, Asayama I, Kambe T, Koga K (2003) Effect of calf-thigh intermittent pneumatic compression device after total hip arthroplasty: comparative analysis with plantar compression on the effectiveness of reducing thrombogenesis and leg swelling. J Orthop Sci 8(6):807-811

20. Gaine WJ, Ramamohan NA, Hussein NA, Hullin MG, McCreath SW (2000) Wound infection in hip and knee arthroplasty. J Bone Joint Surg Br 82(4):561-565

21. Geerts WH, Bergqvist D, Pineo GF, Heit JA, Samama CM, Lassen MR et al (2008) Prevention of venous thromboembolism: American College of Chest Physicians Evidence-Based Clinical Practice Guidelines (8th Edition). Chest 133(6 Suppl):381S-453S

22. Gill SK, Theodorides A, Smith N, Maguire E, Whitehouse SL, Rigby MC et al (2011) Wound problems following hip arthroplasty before and after the introduction of a direct thrombin inhibitor for thromboprophylaxis. Hip Int 21(6):678-683

23. Gomez-Outes A, Terleira-Fernandez AI, Suarez-Gea ML, VargasCastrillon E (2012) Dabigatran, rivaroxaban, or apixaban versus enoxaparin for thromboprophylaxis after total hip or knee replacement: systematic review, meta-analysis, and indirect treatment comparisons. BMJ 344:e3675

24. Guyatt GH, Akl EA, Crowther M, Gutterman DD, Schuunemann HJ (2012) Executive summary: antithrombotic therapy and prevention of thrombosis, 9th ed: American College of Chest Physicians Evidence-Based Clinical Practice Guidelines. Chest 141(2 Suppl):7S-47S

25. Hankey GJ, Eikelboom JW (2011) Dabigatran etexilate : a new oral thrombin inhibitor. Circulation 123:1436-1450

26. Harris WH, Sledge CB (1990) Total hip and total knee replacement (1). N Engl J Med 323(11):725-731

27. Hirsh J, Bauer KA, Donati MB, Gould M, Samama MM, Weitz JI (2008) Parenteral anticoagulants: American College of Chest Physicians Evidence-Based Clinical Practice Guidelines (8th Edition). Chest 133(6 Suppl):141S-159S

28. Hull RD, Pineo GF, Francis C, Bergqvist D, Fellenius C, Soderberg $\mathrm{K}$ et al (2000) Low-molecular-weight heparin prophylaxis using dalteparin in close proximity to surgery vs warfarin in hip arthroplasty patients: a double-blind, randomized comparison. The North American Fragmin Trial Investigators. Arch Intern Med 160(14):2199-2207 
29. Jameson SS, Rymaszewska M, Hui AC, James P, SerranoPedraza I, Muller SD (2012) Wound complications following rivaroxaban administration: a multicenter comparison with lowmolecular-weight heparins for thromboprophylaxis in lower limb arthroplasty. J Bone Joint Surg Am 94(17):1554-1558

30. Johnson R, Green JR, Charnley J (1977) Pulmonary embolism and its prophylaxis following the Charnley total hip replacement. Clin Orthop Relat Res 127:123-132

31. Jones PR, Pearson J (1969) Anthropometric determination of leg fat and muscle plus bone volumes in young male and female adults. J Physiol 204(2):63P-66P

32. Matziolis D, Matziolis G, Perka C (2011) Thromboembolism prophylaxis with dabigatran leads to lower perioperative blood loss than with dalteparin in primary knee arthroplasty. Arch Orthop Trauma Surg 131(12):1739-1743

33. McNally MA, Cooke EA, Harding ML, Mollan RA (1997) Attitudes to, and utilization of, low molecular weight heparins in joint replacement surgery. J R Coll Surg Edinb 42(6):407-409

34. Mengal B, Aebi J, Rodriguez A, Lemaire R (2001) A prospective randomized study of wound drainage versus non-drainage in primary total hip or knee arthroplasty. Rev Chir Orthop Reparatrice Appar Mot 87(1):29-39

35. Muntz J (2009) Thromboprophylaxis in orthopedic surgery: how long is long enough? Am J Orthop (Belle Mead NJ) 38(8):394-401

36. Nadler SB, Hidalgo JH, Bloch T (1962) Prediction of blood volume in normal human adults. Surgery 51(2):224-232

37. Nanni M, Perna F, Calamelli C, Donati D, Ferrara O, Parlato A et al (2013) Wound drainages in total hip arthroplasty: to use or not to use? Review of the literature on current practice. Musculoskelet Surg 97(2):101-107

38. Nieto JA, Espada NG, Merino RG, Gonzalez TC (2012) Dabigatran, Rivaroxaban and Apixaban versus Enoxaparin for thomboprophylaxis after total knee or hip arthroplasty: poolanalysis of phase III randomized clinical trials. Thromb Res 130(2):183-191

39. Parker MJ, Roberts CP, Hay D (2004) Closed suction drainage for hip and knee arthroplasty. A meta-analysis. J Bone Joint Surg Am 86-A(6):1146-1152

40. Villaca DS, Lerario MC, dal Corso S, Napolis L, de Albuquerque AL, Lazaretti-Castro M et al (2008) Clinical value of anthropometric estimates of leg lean volume in nutritionally depleted and non-depleted patients with chronic obstructive pulmonary disease. Br J Nutr 100(2):380-386

41. Walmsley PJ, Kelly MB, Hill RM, Brenkel I (2005) A prospective, randomised, controlled trial of the use of drains in total hip arthroplasty. J Bone Joint Surg Br 87(10):1397-1401

42. Warwick D (2012) Prevention of venous thromboembolism in total knee and hip replacement. Circulation 125(17):2151-2155

43. Warwick D, Bannister GC, Glew D, Mitchelmore A, Thornton M, Peters TJ et al (1995) Perioperative low-molecular-weight heparin. Is it effective and safe. J Bone Joint Surg Br 77(5):715-719

44. Wells PS, Borah BJ, Sengupta N, Supina D, McDonald HP, Kwong LM (2010) Analysis of venous thromboprophylaxis duration and outcomes in orthopedic patients. Am J Manag Care 16(11):857-863

45. Wilson PD Jr (1977) Joint replacement. South Med J 70(Suppl 1):55-60 